\title{
A Multi-Case Study of Entrepreneurial Competencies in Microenterprises
}

\author{
"Tzu-Jiun Yeh" \\ Hung-Jung Chang ${ }^{2}$

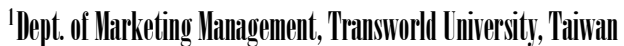 \\ 2Dept. of Business Idminisistrition, Trienswiorld Iniversity, Thiwiwn

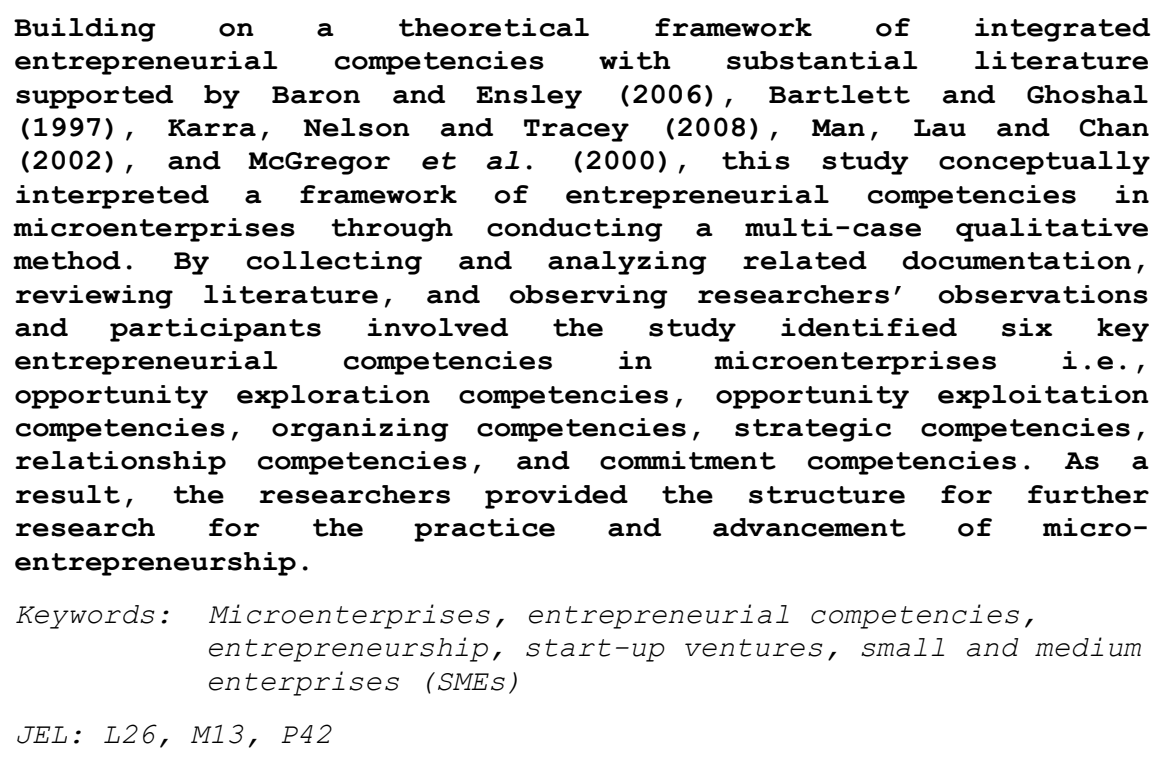

Microenterprises have played a significant role in Taiwan's economic development and carried much weight.

According to the White Paper on Small Medium Enterprises (SMEs) published by the Ministry of Economic Affairs (Wu, 2014), the microenterprises that employ less than 5 persons in Taiwan accounted for 70 percent of all its enterprises; the turnover by these microenterprises accounted for about 10 percent of the total amount and they employed a total of about six hundred thousand people. They had an average annual sales at about NT\$3 million, with averaged fixed assets at NT\$4 million. The contribution of microenterprises to Taiwan's economic development is shown by their role in the information and communication (manufacturing) industry. Despite the percentage of the microenterprises with less than 5 people is considerable in the sector of food and retail sales, those employing less than 5 persons in the information and communication industry also account for 25 percent thereof. As little as the production value of these microenterprises is, they play an indispensable part in supplying components to the big players.

Manuscript received August 15, 2018; revised November 12, 2018; accepted November 20, 2018. @ The Author(s); CC BY-NC; Licensee IJMESS

${ }^{*}$ Corresponding author: euniceyeh2011@gmail.com 
Unlike the microenterprises in any general developing countries, the microenterprises in Taiwan are not running as the only means of making a living for the class of the poor as in most developing countries; instead, many of them are the result of entrepreneurship by individuals after having amassed certain capitals for a higher career development. Their capitals by far exceed US $\$ 1,000$ for those in developing countries, and their growth is considerable, too. As such, many microenterprises in Taiwan are start-up ventures. With a view to create a good environment that helps entrepreneurship, the Government is planning on a start-up platform to simplify the procedure of start-up ventures establishment. Meantime, the Government has knowledge and information centers and consulting windows on entrepreneurship in place for those who are keen to start up an enterprise; it also holds expos of start-up, providing ways of starting up for entrepreneurs. In addition, to strengthen the functions of such start-up platform, the Government will also assist the new enterprises in financing and make effort to reduce administrative obstacles to the establishment of new enterprises.

There are several motivations for the researchers to conduct this study. Micro-entrepreneurship issues related to the entrepreneurial competencies cannot be taken lightly, as the act of entrepreneurship is a swimor-sink matter for entrepreneurs. Many of them bet all they have on it, where the failure of the start-up not only concerns losing job but also leads to indebtedness. When examined, the microenterprises in Taiwan come in two types. Generally they are running as a way of making a living, just like those in developing countries, while others are the action of entrepreneurship by elites who seek higher development after having accumulated certain level of funds and techniques. Hence, it is more necessary to address the current issues of entrepreneurial competencies needed by microenterprises to promote the effectiveness of their development.

Since the concept of "entrepreneurial competencies" became frequently cited in strategic management research, a good number of researchers have explored this field actively, while the studies with competency approach tend to increase in number (Baron and Markman, 2003; Man, Lau and Snape, 2008; McGregor et al., 2000; Schmitt-Rodermund, 2004). For example, Chandler and Jansen (1992) believe that the entrepreneurial competencies of an entrepreneur have greater influence on corporate performance. 


\section{Yeh \& Chang}

Chandler and Hanks (1994) believe that the entrepreneurial competencies of an entrepreneur help the enterprise in seizing opportunities and elevating the level of corporate performance. Similarly, Hatch and Zweig (2001) found from probing 50 rapidly developing enterprises that the ultimate drive force with which an enterprise realizes rapid development is its adaptive ability, which is usually embodied through the exhibition of entrepreneurial competencies. Man, Lau and Chan (2002) conducted in-depth exploration in entrepreneurial competencies from integrated perspectives. They defined entrepreneurial competencies by several aspects of opportunity competencies, relationship competencies, concept competencies, integration competencies, strategy competencies, and commitment competencies. These studies more or less demonstrated that the influence of entrepreneurial competencies on the performance of start-up ventures truly exists.

Yet, a complete structure of entrepreneurial competencies integration in micro-entrepreneurs has not been established. Building on the theoretical framework of the entrepreneurial competencies with many studies conducted by Baron and Ensley (2006), Bartlett and Ghoshal (1997), Karra, Nelson and Tracey (2008), Man et al. (2002), McGregor et al. (2000), this study conceptually interprets a framework of entrepreneurial competencies integration in microenterprises through adopting a multi-case qualitative method, documentations collected and analyzed, literature reviewed, and the researchers' observations and participation concludes six key elements i.e., opportunity exploration competencies, opportunity exploitation competencies, organizing competencies, strategic competencies, relationship competencies, and commitment competencies.

The remainder of the study is laid out in the following manner. Section 2 comprises literature review. Section 3 describes methodology. Section 4 summarizes brief overview of multiple cases in the study. Section 5 presents discussion. Section 6 addresses conclusion. Section 7 depicts implications. The limitations and future directions are presented in Section 8.

\section{LITERATURE REVIEW}

\section{Definition and Characteristics of Microenterprises}


According to a 2014 monographic report by the Small and Medium Enterprise Administration, overseas definitions for microenterprises are as follows. The Department of General Services (DGS) division of US Government mentioned that microenterprises are a part of small enterprises, and the DGS-defined scope is any small enterprise with average annual revenue below US\$2,750,000 and a manufacturing factory with fewer workers than 25, while the Association For Enterprise Opportunity (AEO) of US specifically defined an enterprise by with under 5 employees or start-up capital under US $\$ 35,000$, whereas a microenterprise can be any type of business run in any way, including services, PC sale \& repair, food processing, apparel, textile, art craft of any size, and the list goes on (Small and Medium Enterprise Administration, 2014). According to the studies by Asia-Pacific Economic Cooperation (APEC) and other overseas policies and measures, few governments have made laws specifically on microenterprises; Taiwan is no exception. Most of the countries incorporate microenterprises in the category of SMEs when making the law, where as the standard for determining a microenterprise, the definition of fewer than 5 employees is widely adopted (Chao, 2003).

Taiwanese Definition: According to Article 3 of the standard for recognizing SMEs, what is referred to as small-scale enterprise is a business that meets either of the following two criteria: a business in manufacturing, construction, mining and quarry industries that employs fewer than 20 persons on a regular basis (Chao, 2003); a business in agricultural, fishery, water resources, power, natural gas, commercial, transport, warehouse, telecommunication, finance and insurance, real estate, industrial service, social service, and personal service industries that employs fewer than 5 persons on a regular basis (Chao, 2003).

A 2010 report by the Global Entrepreneurship Monitor (GEM) proposes a concept of necessity-push entrepreneurship and opportunity-pull entrepreneurship (Wen and Hsieh, 2010). The former refers to the entrepreneurial activity taken due to no other choice of or dissatisfaction with the choice of employment available, and the latter refers to the entrepreneurial activity taken in pursuit of a commercial opportunity. It is the necessity-push entrepreneurship that is the category to which the microenterprises under investigation herein belong.

The starters of microenterprises display the apparent characteristics of necessity-push entrepreneurship. 


\section{Yeh \& Chang}

They are mostly at the age under 25 or over 45 , and with lower educational background, with elementary or junior high school education being the majority. The starters of microenterprises have short-term expected return on investment than the opportunity-pull entrepreneurship to recover their costs of investment, as they are anxious to get rid of the awkward situations that existed before the entrepreneurial activity, in order to avert the risk of investment. For starters of microenterprises, the starting capitals come from personal funds, family and relatives, partnership, and, only in few cases, bank loans. Regarding technical obstacles to entrepreneurship, they generally opt for the trades with lower technical obstacles and intend to keep away from those with higher technical obstacles.

\section{Definition of Entrepreneurial Competencies}

Entrepreneurial competencies are defined as the ability to identify and acquire or innovate in new markets given the entrepreneurial opportunity and the need for resources (Karra et al., 2008). Entrepreneurial competencies are the key skills and intrinsic knowledge possessed by the entrepreneurs, and are an intellectual capital that individuals possess as a high-level feature, which includes personality, skills and knowledge, all deemed as total abilities with which entrepreneurs can successfully fulfill their duties (Man et al., 2002). Entrepreneurial competencies also are the combined abilities required for entrepreneurs to be competent for their roles, and are associated with the birth, survival and growth of the new enterprises (Chandler and Hanks, 1994; Chandler and Jansen, 1992; Krueger et al., 2000; Ma and Tan, 2006).

\section{The Timmons Model of Entrepreneurial Process}

The Timmons model of entrepreneurial process involves a market driven opportunity, availability of a good team and required resources as driving forces before starting the venture and concludes that the success of an entrepreneur depends upon the ability to balance all these three forces. These three driving forces of entrepreneurship remain interlinked as circles, with any change in one force having an impact on the other two. As the change, innovation and unique ideas are the core of the model and can be extracted from personal thoughts and market analysis (Timmons, 1989). The business plan also provides the language of code for communicating the quality of these three forces and their fit and balance. In addition, Moises (2012) proposed that the entrepreneur's legacy is to create a positive influence without harming environment, the 
community, or society, the concept of sustainability seems to become as the basis in the entrepreneurial process.

The Timmons model advocates strongly that entrepreneurship is nothing but opportunity driven. The entrepreneurial process starts with opportunity that is much bigger than either the talent or ability of the team or initial resources available to the team. Opportunities are more crucial than the talent or capacity of lead entrepreneur and the team because a right opportunity exploited ensures long-term success of the business (Moises, 2012). Once the entrepreneur recognizes an opportunity, he/she begins to start a venture by putting together the team and gathering the adequate resources. The Timmons framework places special importance on the team and also believes a good team as indispensable for success. Timmons (1999) also concluded that the size and type of opportunity determine the level and extent of resources required. The role of the entrepreneur in organizing the resources include building an adequate resource base to draw from when required and drawing up a business plan through a fit and balance method that balances the available resources with the opportunity and the potential of the team (Moises, 2012).

In the light of the literature review of entrepreneurial process model proposed by Timmons, Shane (2003) argued that Timmons framework misses the social and environmental perspectives to the entrepreneurship. However, the conceptual framework of the study for the entrepreneurial competencies focuses on the social and environmental factors which have been concluded in the relationship competencies, strategic competencies, and commitment competencies.

\section{Constructs of Entrepreneurial Competencies}

In constructing the conceptual framework of entrepreneurial competencies for microenterprises, this study summarizes, by making reference to the research by Baron and Ensley (2006), Bartlett and Ghoshal (1997), Man et al., (2002), and Karra et al., (2008), their contents regarding entrepreneurial competencies. The contents of entrepreneurial competencies comprise the following six key elements:

1. Opportunity Exploration Competencies: These are one of the important abilities a successful entrepreneur must have (Vaghely and Julien, 2008). Kirzner (1979) argued that entrepreneurs are identifiers of opportunities rather than organization creators in general meaning. The unique function of entrepreneurs 


\section{Yeh \& Chang}

is being able to restore market balance through identifying and exploiting opportunities. Bartlett and Ghoshal (1997) further generalized the competencies regarding entrepreneurial opportunities as the ability of entrepreneurs to seize and incubate market opportunities by various means, which lies deep in entrepreneurs' act of identifying, exploiting and developing opportunities. As such, entrepreneurial opportunities are found, recognized and built (Baron and Ensley, 2006; Sarason, Dean and Dillard, 2005; Shane, 2000).

2. Opportunity Exploitation Competencies: The sequence of exploration-then-exploitation during entrepreneurship has been recognized in academics (Aldrich, 1999; Choi, Levesque and Shepherd, 2008) and in practical field (Block and MacMillan, 1985) as well. Entrepreneurial opportunity exploitation competencies are entrepreneurs' capability of developing, after exploring opportunities, new creativity, fast creation of products or services, uncovering new market sectors, having received benefits from developing new production, marketing and management, and building their new enterprises and organizations (Chandler and Hanks, 1994). During the stage of opportunity exploitation competencies, entrepreneurs take accumulation of knowledge of products and market seriously (Choi and Shepherd, 2004; Rice, 2002).

3. Organizing Competencies: Chandler and Hanks (1994) proposed organizing competencies of entrepreneurs as the ability in relation to the activities like relocating internal and external resources of the new enterprise, forming start-up teams, leading one's subordinates, and administering training and monitoring. Entrepreneurs should focus on the effective acquisition of external resources in starting up an enterprise, while they should be able to allocate and harness existed resources effectively. Also, the orientation of efficiency and attention to quality job and monitoring for effective operation are necessary competencies of entrepreneurs in managing different functional fields (McClelland, 1987). Baum (1994) further asserted the significant, positive relation between organizing competencies and new enterprise performance, and believed that these organizing competencies need to consist of the knowledge, skills and abilities in different areas of function management. In addition, entrepreneurs should be able to effectively manage the employees at new enterprises so as to coordinate the internal behaviors; entrepreneurs should possess the abilities of authorizing, training and guiding, and working with others. Hence, new enterprises 
require the entrepreneurs to possess the abilities of leading, controlling, monitoring, organizing and relocating the organization's internal and external resources, as well as their effective organization and planning in the function areas of the new enterprise.

4. Strategic Competencies: These are the abilities of entrepreneurs to deal with the affairs in various function areas and uncertainty of external environment in the strategic directions; such competencies can only be acquired through extended practice and learning (Man et al., 2002). Being the only decision maker at new enterprises, entrepreneurs should specify directions for development of the enterprises and be able to set plans and execute the strategies. Subject to the fact that entrepreneurship is faced with complex problems most of the time, entrepreneurs are destined and required to possess certain analytic abilities, including decision skills, making references and comprehending complex information, assuming risks and innovating (Chandler and Jansen, 1992). Gasse et al. (1997) emphasized that the scope of strategic competencies also covers creating necessary strategic alliance. Hence, strategic competencies require entrepreneurs to command the big picture, set up specific goals of action, and effectively implement the strategies for the purpose of realizing predefined goals.

5. Relationship Competencies: These are the abilities of entrepreneurs to drive interactions between people or between people and organization. Entrepreneurship is a process of identifying, utilizing and exploiting opportunities in the context of scarcity of resources. Entrepreneurs should finish an important task of paving the way for the entrepreneurship through interaction and connection, and form the advantages of the new enterprise. Meantime, entrepreneurship is a process of maintaining and creating new relationships by entrepreneurs, which embodies socialization of new entrepreneurs. Bird (1995) described relationship building as entrepreneurial bonding and believed that it includes not only relationship building but also relationship restoration. In addition, rather than fighting alone, entrepreneurs need to effectively handle the relationship with partners and employees, dissolving cognitive conflicts within organization and avoid emotional conflicts. Hence, entrepreneurs should possess the abilities of building relationships, communications, persuading people and interacting with people in the community or society. They should be able to strike up good interaction with individuals or of individuals within groups and communities. 


\section{Yeh \& Chang}

6. Commitment Competencies: These are the abilities that drive entrepreneurs in sustainable operation. Entrepreneurship being not easy, entrepreneurs tend to have extraordinary abilities in assuming responsibilities, dedicating themselves and take preemptive actions, and have intensive momentum that drives the new enterprises from beginning through to completion. There are times when they are forced to take action ahead of the environment in order to keep the new ventures away from external impacts (Chandler and Jansen, 1992); as such, due to intensive drive of mission, they have remarkable perseverance against external disturbance, which are the commitment competencies that enable them to keep on operating and realize benefits for suppliers, employees, customer and risk investment.

\section{Uniqueness of the Competencies for Entrepreneurs}

Ahmad (2007) explored the relationship between entrepreneurial competencies and business success in the context of SMEs in Australia and Malaysia. According to Ahmad (2007) in Soejono, Mendari, and Rinamurti (2015), analysis of interview data identified twelve competencies i.e., strategy, commitment, opportunities, knowledge, organizing, decision making, relationships, learning, personal, technical, risk taking, and social responsibility. The results indicated that entrepreneurial competency was a strong predictor of the business success in Australia and Malaysia (Soejono et al., 2015:34). Ahmad et al. (2010) examined the effect of entrepreneurial competencies and the moderating impact of the business environment on business success in small and medium sized enterprises in Japan. They found that competence of entrepreneurship was a strong predictor for the success of SMEs business in Japan.

A great deal of research describe that there is a positive relationship between human capital and entrepreneurial performance that makes entrepreneurs more efficient in how they run their businesses and perform complex tasks (Marimuthu, Arokiasamy and Ismail, 2009; Unger et al., 2011). Meanwhile, human capital can be defined as the attitudes, commitment, opportunity exploration, values, experience, relationship, organizing, education, skills and abilities, which assists the firm founder and his team in the tasks of starting, running and growing the business (Marimuthu et al., 2009; Unger et al., 2011).

\section{METHODOLOGY}


This study made reference to Yin's (2003) research procedure, which includes uncovering research problems, identifying research objectives, gathering documentary materials, having in-depth understanding of the cases under study, modifying research problems, making research design, analyzing, drawing conclusions and giving implications.

The purpose of this study was to understand the contents of entrepreneurial competencies needed in microenterprises in order for the practitioners to better understand the entrepreneurship. In gathering documentary materials, this study explored the documents on entrepreneurial competencies to form the theoretical framework of literature. Theoretical framework building was followed by a multi-case study to probe the cases. In the examination of the cases, documentary theories not only helped the researchers set the appropriate research design and facilitate data gathering but also were an important tool of summarizing and analyzing the materials on the cases under study. This was a multi-case study, intended to follow the replication logic in order that the cases under study (1) produce the same results, being a literal replication; and (2) this is a theoretical replication, as expected causes produce different results from prior research (Yin, 2003).

During the process of research and analysis, this study engaged in the data collection involved by the cases under study and held in-depth interviews with the participants involved in those cases to have better understand of the entrepreneurial competencies therein. That was followed by integrating the researchers' analyses on the cases under study and literature supported theoretically to derive final findings as recommendations for practitioners and as the research results for strengthening the contents of the constructs on entrepreneurial competencies. Purposive sampling was employed to select the five company founders who participated in this study and constructed her/his own reality, experience, or perspective regarding entrepreneurial competencies when launching a successful venture. The study selected research subjects based on the following features: one, the cases were companies that were all established in Yunlin County, Taiwan and were in similar environmental conditions based on small-sized business, each being an enterprise in the service sector founded with fewer than five employees; and two, each entrepreneur has successfully operated a company that has been in business for at least three years since the company was 


\section{Yeh \& Chang}

founded and earned more than US $\$ 150,000$ per year. Age of subjects were ranged from 28 to 65 and years of running business from 5 to 30 . The fields of five service industries conducted in this study comprised of beverage services, catering services, agricultural commodities services, and truck transportation services.

Secondary data from these microenterprises was collected through documentary sources such as strategy plans, annual reports, and web pages. Primary data was collected by using unstructured and faceto-face interviews with the company founders in their workplaces conducted each for lasting approximately 40 to 50 minutes. Interviews were recorded and transcribed by the researchers as part of the data analysis process. The viewpoints of the different participants from each case were also compared by representing the entrepreneurial process of each firm as a narrative text. The data analysis focused on how different types of entrepreneurial competencies were utilized to implement the new ventures and the sources of these competencies.

\section{BRIEF OVERVIEW OF MULTIPLE CASES IN THE STUDY}

Company A was conceived by its three directors, all in a family, who had long deliberation over the low wages, long work hours and least freedom in where they did part time as well as being often bossed around and given hard time. They decided to put NT\$250,000 as capital in the drink business. In 2009, when in discussion on the entrepreneurship, the entrepreneur told his family directors about his own on-the-job experience in drink business and clearly stated the risks of entrepreneurship. The family directors were convinced of low starting cost in drink business while they had made sound assessment of the geographic condition for their business and were sure of controlling the business hours well by themselves.

Company B, Er-Ji-Shuan, was founded by the owner and his wife in 1988 with a startup fund of NT\$15,000. In the beginning, they did business as a street vendor, but considering the difficulty of controlling hygiene and quality, they converted to a physical shop a year later, which allowed them to control business hours freely and on a larger scale.

Company $\mathrm{C}$ is in the coffee industry. It is a partnership venture between two friends, started on Aug 8 , 1999 with a NT\$600,000 fund. It began as an unknown coffee shop and gradually developed a group of loyal, coffee-loving customers. When there were more words of mouth, the shop became known. Later, they 
also acquired a coffee truck of novel style, which travels the island serving freshly brewed aromatic coffee to coffee connoisseurs.

Company $D$ is a fruit vendor, run by a Yang family. They started with a NT\$1 million fund. The entrepreneurship is because this family has experience in selling fruits and vegetables; they have connections in this field as well as sale channels are also available. Each year, on the first days of summer season, the entrepreneur in this case starts to bring in massive amount of watermelon directly from several farmers; doing so needs a big warehouse along with a place in the shade to keep the watermelon from spoiling. Meantime, they make the over-mature watermelon into juice for selling.

Company $E$ is a transporter of fish stock, started by a couple named Chang with a NT\$2.5 million fund. The entrepreneur in this case decided in this entrepreneurship because he compared the transport of fish with traditional transport of other food ingredients like vegetable and fruits in terms of the process and profit, and discovered the former has more profit.

\section{DISCUSSION}

Godfrey and Gregerson (1999:41) argue that to uphold a competitive advantage in this turbulent environment requires "entrepreneurial competences to identify, develop and complete new combinations of existing asset bundles or new unmet opportunities". From the literature reviewed above, it appears to be clear that different competencies need to possess to gain credibility for the start-up ventures. There are six key elements of entrepreneurial competencies concluded in this study based on literature and case exploration, namely opportunity exploration competencies, opportunity exploitation competencies, organizing competencies, strategic competencies, relationship competencies and commitment competencies, which contain most of the business skills and entrepreneurship abilities. They are analyzed in detail as follows:

\section{Opportunity Exploration Competencies of Microenterprises}

Company A was founded on February 2009, and first they need to know the market in Yunlin, Chiayi and Tainan regions for beverage at that time. In the almost saturated market for beverage, however, what consumers concern most is the taste of beverage, new flavors and price. The entrepreneur in this case did search for information in detail, but, above all, he had bought drinks at a number of drink shops for careful 


\section{Yeh \& Chang}

comparison. Based on such information, Company A prepared its new flavor unlike any one in the market, while in terms of price, it took the strategy of very affordable price in exchange of increased sales.

Company B was founded in 1988 when in Douliu City there were only two physical stores as its competitor. At that time when convenience stores had yet to appear it was literally a monopoly market. Before Company B became the first physical store in the name of Er-Ji-Shuan to increase competitiveness, it had originally started as a street vendor with no fixed locations. In the beginning its products and flavors were identical to those of the competitors, but, the owner constantly developed new items in order to have more customers come back; pricewise, the owner did not increase until its competitors had done so.

Company C was founded on August 1999. At that time the entrepreneur in this case had to have better understanding of the coffee industry in Gukeng and assessed the business condition of nearby café and guesthouses in the region. It was at that time that Yunlin County held the first Taiwan Coffee Festival, to which the whole nation responded enthusiastically and which sparked the booming growth of coffee-related industries in Gukeng as it is today. Coffee trucks are like a stylish mobile street vendor. In order to attract consumer widely, it is crucial that the trucks have an appearance that appeals to consumers. A winner is a truck at which consumers decide to stop and take picture. On top of that, if its products stand out, then customers who pursue new items would become its main customers in the future.

Company D was founded in 2007, April. In the first beginning, they had to have better understanding of the customers who were just passing by and how the crowd moved at that time. While the market for watermelon was almost saturated, what consumers concerned most were the taste, freshness and price of the watermelon. Besides acquiring detailed information, above all, the owner had purchased watermelon from a few sellers to compare the quality and productivity. The owner gained the edge over his competitors in terms of wholesale price for this fruit.

Company E was founded in 2011, June. At the start, they had to have insights into the condition of demand and supply as well as the distribution system in the fish markets in northern, central and southern Taiwan, because for fish, those markets were mostly pure fish market. And, given a saturated market for transport, in which a multiple of known delivery services (such as T-Cat, TJ Transport and HCT Logistics) 
dominated, the transport charges were high. Company E thus targeted at fish and oyster for transport.

Summary: The above exploration and analysis indicate that regarding opportunity exploration competencies of Microenterprises A, B, C, D and E, they took the location in market very seriously and were highly aware of consumers' perception of product price, taste, quality and service. Company E was particular about the cooperation with certain corporations on distribution.

\section{Opportunity Exploitation Competencies of Microenterprises}

At Company $\mathrm{A}$, the owner had to constantly attempt at discovering new drink recipes in their startup process

to meet the consumer's preference for new flavors. They also needed to explore new regional markets gradually, where through night markets, shops and unknown drink shops, they came to know the price range suitable for consumers at that time, and had insight into what made consumers buy drinks (e.g., thirst, hot days) and when they bought, which were all dynamic information an entrepreneur and operator should be aware of.

Company B revealed new merchandise constantly in order to cater consumers' curiosity in flavor, challenging them on their impression on Er-Ji-Shuan products. As with the flavor of product, the owner kept improving and developing to produce the pocket pancake and deep fried dough stick that consumers wanted to savor again and again after having eaten it and that made customers associate with Er-Ji-Shuan. By doing so, the company not only effectively made more customers come back but also made Er-Ji-Shuan a known brand, and marched toward a successful operation of franchising and chain.

In the startup process, Company $\mathrm{C}$ being aware of consumer's curiosity and liking of new items, designed creative and unique appearance and made latte arts in every cup in graph and creative images that customers enjoy to make them, especially couples, stop at the shop. The owner knew how to make the coffee more aromatic and creamier and tried preparing coffee of various flavors to cater to customer taste buds. Meantime, they explored market in new areas; by means of physical shops or tourist sites, they tried to understand how they were welcomed by consumers. They innovated so as to build their own brand.

During the process of startup, the owner of Company D had to rigorously select the season-fresh watermelon, controlling the sweetness and freshness at every batch, as well as maintain stable supply and 


\section{Yeh \& Chang}

quality of the fruit. On the other hand, they expanded to new market regions, where it took understanding of a market, containing commercial neighborhood, targeted customers, busy hours, consumption power and frequency, to be successful in it.

Company E operated truck delivery of a variety of seafood (e.g., shellfish, fish and crab) for fish market in their startup process, in which they also came to know the dynamics of the market and were able to expand into new market regions. In this case, Company E discovered the possibility of operating return trips to make good use of the truck that would otherwise have been empty by carrying seafood to traditional markets, which not only did without wasting the time of return trip but also increased income.

Summary: The above investigation and analysis reveal that in opportunity exploitation competencies, Microenterprises A, B, C, D and E were highly aware of the general consumers' behavior of purchase and the company's position in the market.

\section{Organizing Competencies of Microenterprises}

Company A started with test run on a mobile drink truck at the Humanity Park of Douliu City, Yunlin County to see if its beverages met the consumers' need (e.g., seasonal flavor, innovated taste and price). At the stage of test run, the entrepreneur did everything alone, from preparation of ingredients to preparation of product drinks, without any employees. As such, in a try-an-error manner, he accumulated solid organizing ability as an entrepreneur. The practice of material purchase, cashier work and accounting allowed the entrepreneur to clearly understand how to set the price for the products after the test run.

The owner of Company B controlled the product quality rigorously and often adjusted his range of items appropriately following customers' opinions. They started with the couple themselves along with 3-4 employees, but, the owner handled all the products sold at the shop alone. He had run a snack stool for years before he started this shop, owing to which he was quite skilled with the basics, for example, egg pancake sheets and fried dumplings both were developed by him. The couple also was the sole contributor to the startup capital. In purchasing, their suppliers were mainly from Douliu City where the shop is located, with whom this entrepreneur has long kept good cooperation. Financially, they operated solely on cash basis, and the owner kept the books alone. 
Company C started with test run in the Gukeng Green Tunnel, Yunlin County on a coffee truck for three consecutive days. Without any employees, this entrepreneur made it through the stage of test run, from preparation to closing. The test run allowed full understanding of whether his coffee products met the need of the local consumers (regarding taste, quality and price etc.).

Company $D$ is in the fruit trade, namely watermelon. The company is run by the entire Yang family. The father was the founder and owner, but all the family members work together on the product preparation, consisting of producing skills, purchase, market analysis, finance and personnel allocation; they do well at the organization in entrepreneurship. For marketing, they began with the residents in Daja Township, Taichung County, their friends and relatives as well as passers-by; then they expanded to townships and cities or utilized the main events sponsored by the county government. As they have successfully put themselves on the map, they made use of the 2016 Cycling parade sponsored by Taichung City, for example, and succeeded in selling a lot of watermelon to Taichung City Government.

At Company E, it began with a purchased 17 ton big truck and the entrepreneur personally took care of all the goods delivery. The company has sound financial standing with capital solely contributed by the family, at NT\$2.2 million; and entrepreneur bought NT\$300,000 insurance for himself. Where the wholesalers are buying aquaculture fish in huge amount based on the aquaculture that has grown significantly over the years, this entrepreneur possesses massive network of wholesalers in fish markets in northern, central and southern Taiwan and knows the demand of fish transport market well.

Summary: The above exploration and analysis indicate that the organizing competencies Microenterprises A, B, C, D and E can be examined in five aspects. In respect of interpersonal relationship, these companies acquired relevant information through their friends and relatives and loyal customers; in respect of finance, they practice consolidated financial statements incorporating simple accounting; in respect of techniques, they acquired by working part-time or independent investigation in related experiences; in respect of market, the first priority for these companies is deploying in large events, tourist sites and on the routes of passersby, while Company $E$ is comparatively unique in a way that it goes chiefly through seafood suppliers and fish markets ; in respect of purchase, these companies employ strong cooperation with suppliers and 


\section{Yeh \& Chang}

wholesalers.

\section{Strategic Competencies of Microenterprises}

The operative mode of Company A was drinks on wheel; so, its strategy formulation was less complex than with a physical shop. After all, at a physical shop, the rental and other costs tend to make drinks more expensive. Yet, in this case of study, the selection of beverage truck saved the costs of shop rental, interior decoration, public utility bills and personnel, which gave the company somewhat advantage. As a result, the company enjoyed flexibility and margin in terms of pricing over its competitors.

Company B adopted a strategy of cost advantage when starting up; as the title of the building for the shop belongs to the entrepreneur of this case, a considerable rental was saved. Meantime, in product pricing, the entrepreneur of the Company B practiced differentiation, where despite the competitors increased their prices due to material cost up, he was able to maintain his price unchanged because he was capable of absorbing the cost increase. In promotion, when the first shop opened, he held a three-day promotion sale with buy-10-get-1-free, free sampling, and an eat-all-you-can contest, which successfully attracted massive consumers and students.

Company $\mathrm{C}$ started up in the business mode of coffee truck, which was not as complex as a physical coffee shop to draw up strategies. Yet, the selection of business sites became critical because a truck converted into coffee shop on wheel has not met the law in Taiwan. While a coffee truck did not provide glamorous decoration or a comfortable indoor environment as physical shops did, doing without the trouble of rental, interior decoration and personnel cost allowed choosing coffee beans of better quality and more competitive pricing, a desirable strategy in terms of coffee quality and price.

The operative strategy Company $D$ adopted in starting up was using a shop the entrepreneur himself owned as a selling outlet, which saved handsome fixed costs like rental among others. This entrepreneur sells watermelons that he bought at big batches from the sources (namely, the farmers), picking every watermelon personally, so, the product quality was stable and guaranteed. Based on a one-hand distribution strategy and bargain due to large-quantity purchase, the entrepreneur had the edge in the competitive market. In promotion, he offered juice on a buy-5-bottles-get-1-free basis, not only increasing his sale but 
also helping the farmers with the problem of over-production effectively.

Company $E$ had an operative mode of delivery of single seafood when starting up. The strategy was not as complex as the transport of goods by the known delivery services or large transporters to draw up. The Company being an independent firm delivering one single article, its strategy for cutting in the fish delivery market was necessarily finding more cooperative suppliers. For example, as mentioned above in Point 2, on the return trip from delivering to wholesalers, the owner bought catches as a wholesaler and took back to traditional markets for selling, which added more revenue.

Summary: The above exploration and analysis reveal that in the strategies as strategic competencies, these microenterprises all exercise promotion sales to significantly increase the sale of products. In market strategy, their local positions are different with the different industries. In product strategy, each of the companies pays full attention to the product quality, other expenses and developing products loved by consumers responding to each industry. In price strategy, every company adopts low cost and low price, plus increasing production efficiency. In distribution strategy, Company A acquired business information from the relevant industries, while Company $E$ is unique in that it is in the seafood industry, but its central service is carrying its purchase on the return trip of delivery.

\section{Relationship Competencies of Microenterprises}

At Company A, the manager's ability of communication, transaction and interaction with shareholders and customers matters very much. In entrepreneurship, the investors were the entrepreneur himself and his parents, who needed to have deep discussions and assessment of the constant innovation of products to respond to the competitive and changeable market. As different views and prejudice are inevitable, they solved it with good and positive attitude to avoid confrontation.

In respect of customer demand, the founder of Company B took time to find that consumers now tend to eat smart than eat a lot because they pay more attention to $\mathrm{CP}$ value of diet. He thus sought keenly refinement and nutrition in his product R\&D. In respect of service, this entrepreneur, who sees the employees as his family and is hands-on to everything and wants to create kind and warm atmosphere in his shop, asks every employee to smile warmly with their heart at all times greeting every customer. In addition, 


\section{Yeh \& Chang}

he uses the philosophy of "customer first" for his entrepreneurship.

Company $C$ is a partnership between two persons. At the hard start, as they were in one boat, they worked hand in hand closely, in one heart, to face the market of fierce competition. To make breakthrough so as to effectively increase the creativity, value and uniqueness of their products, it takes an operative ideal shared by the two and making efforts together. Good communication skills and interaction with customers also facilitate satisfactory actions, making their enterprise successful.

In relationship competencies, to Company $\mathrm{D}$, the abilities of managers and employees communicate with customers and interact with upstream and downstream businesses are crucial. In entrepreneurship, the members of the organization should form harmony and build good teamwork, which needs constant reciprocal communication and coordination. The company's founder has always dealt with the customers and the suppliers in good faith and fairly with all people. He has done his best to ensure good quality of the watermelon, and never added artificial colorants or other hazardous substances in the juice. He has taken every careful step with effort with an aim of sustainability.

At Company E, its starter has been engaged in the wholesale of seafood over years, accumulating experience and strong connections with supplier, with which it has kept good communication and interaction. Where efficiency of time is what large wholesalers of seafood and fish demand, the owner of Company E, who constantly needs to travel the island of Taiwan north to south, both ways, provides customized services. Under contract, Company $\mathrm{E}$ is sure to fulfill its commitment to customers whether or not the contracted customers need no service on some days, or even when there is only one trip made. This entrepreneur delivers and satisfies the customers to make them loyal.

Summary: The above exploration and analysis indicate that in respect of relationship competencies of Microenterprises A, B, C, D and E, they pay most attention to innovation on product taste, product quality and corporate owner's attitude to cater to customer demand. In respect of supply, they rely on the cooperation from customers, corporate owners and suppliers. Regarding connections, they build connections through friends and relatives, and they possess good communication skills. Company $E$ is unique for what matters most in relation to cooperative firms is the quantity of cargo, and the requirements of customers and 
corporate owners. In efficiency, small trucks are used to gather goods before loading them onto large trucks for smooth operation; the company always arrives at destinations on time or ahead of required timeline to maximize transport efficiency.

\section{Commitment Competencies of Microenterprises}

Company A started in the drink business and, before startup, had located a number of suppliers of ingredients and packaging materials who could cooperate for long term. Those suppliers provide on-time delivery service. In operation, the company has to clearly advise the customer of what kind of water and the ingredients with which the beverages are made, to allow the customers to feel assured to eat and drink. By doing so, this company does make commitment as a corporation to the customers.

Company B operates in the food and beverage industry and demands a large amount of raw material. For those materials, the entrepreneur in this case under study keeps very good relationship with the suppliers who are all located in the area of Douliu City. They are highly cooperative with high efficiency of delivery. The manager hand picks all the raw materials of good quality, and he ceaselessly develops innovative products to cater to the needs of consumers. With management efforts over years, this entrepreneur has made this business a long-stand brand and expanded the scale to a chain operation of six shops. The owner has always required every shop under his management to strictly control the quality of ingredients because quality guarantee means long lasting reputation of the corporation as well as the best commitment to consumers.

Company $\mathrm{C}$ was founded as coffee industry. Before starting up, the entrepreneur had located several wholesalers of coffee beans that can cooperate for long term. In order to control the coffee bean quality and build sound means of communication to ensure fresh and outstanding quality and stable supply, the entrepreneur hand picks the coffee beans and surveys the production environment; he is able to discuss, face to face, and solve problems that occur.

Company D was founded as fruit and vegetable business. The entrepreneur had known the fruit and vegetable market as well as a number of fruit farmers (suppliers of watermelon) well before his entrepreneurship. Every fruit farmer in cooperation provides on-time delivery service. The entrepreneur 


\section{Yeh \& Chang}

selects watermelon by himself in the farms and put chops on what he picks to ensure the quality is fresh and outstanding. He also takes initiative in caring about the growing and harvesting of watermelon, as he sells nothing but the seasonal fresh fruit. In management, he insists in sharing all information on the water used to make watermelon juice and on the origin of the fruit with customers. As such, this company does make commitment to the consumers.

The entrepreneurship of Company $E$ is as a delivery service of one single seafood. Before the startup, the entrepreneur had located firms that can cooperate for long term. Apart from the firms currently under cooperation, this business scale should be able to grow continuously. Once the cooperative firms increase, the manpower and trucks will increase, too. Because the cooperative firms have been satisfied with the company's efficiency in delivery time and service of cooperation, this company does make commitment to the consumers.

Summary: The above exploration and analysis reveal that in commitment competencies, Microenterprises A, B, C, D and E are more focused on product quality and costs when facing product commitment; they are more focused on consumer's satisfaction with product and quality of firm service when facing commitment to customer; they are more focused on cooperation with firms on purchase when facing commitment to supplier.

\section{CONCLUSION}

This study explores and analyzes broadly in five cases of microenterprise and concludes as follows: 1 . In opportunity exploration competencies, the microenterprises are more aware of the recognition by local markets and consumers. 2. In opportunity exploitation competencies, the microenterprises are more aware of focusing on accumulation of knowledge of products and markets. 3. In organizing competencies, the microenterprises are more aware of integration of inter-personal, procurement, technical, market and financial resources. 4. In strategic competencies, the microenterprises are more aware of setting specific goals of action for the corporations, including integration of promotion strategy, market strategy, product strategy and distribution strategy. 5. In relationship competencies, the microenterprises are more aware of content integration of customer-corporate relationship and organizational interactive relationship. 6. In 
commitment competencies, the microenterprises are more aware of integration of customer satisfaction and ability of sustainable operations. These competencies enable firm founders to identify and assess market opportunities; to set up realistic and measurable goals; to secure resources required; to produce and service the market; to handle conflicts effectively and to accomplish overall organizational efficiency, as well as effectiveness that leads to the growing of the business (Botha, Vuuren and Kunene, 2015:56).

This study has filled a theoretical gap in the literature. Although the entrepreneurial competencies of microenterprises have been researched individually in the past, this study is well-defined from others in the literature in constructing the complete and conceptual framework of entrepreneurial competencies integration (e.g., Baron and Ensley, 2006; Bartlett and Ghoshal, 1997; Karra et al., 2008; Man et al., 2002; McGregor et al., 2000), which is also in line with the Timmons Model of the entrepreneurial practice (e.g., Timmons, 1999; Timmons and Spinelli, 2008).

\section{IMPLICATIONS}

The researchers were motivated to conduct this study since previous research has not significantly founded a complete and conceptual framework of entrepreneurial competencies integration in microenterprises. The results of this study indicate that there are six key entrepreneurial competencies i.e., opportunity exploration, opportunity exploitation, organizing, strategy, relationship, and commitment with substantially empirical evidences and literature support provided by Baron and Ensley (2006), Bartlett and Ghoshal (1997), Karra et al. (2008), Man et al. (2002), and McGregor et al. (2000). According to Timmons Model (1989), the entrepreneurial process considers the exploration and recognition of opportunity, the decisions regarding the exploitation of the opportunity, competencies to organize and acquire any adequate resources and strategies to strengthen the development of team in order to execute the new business. For the theoretical and entrepreneurial contributions of the study, this study has explored the link between Timmons Model of the entrepreneurial process and the six entrepreneurial competencies concluded in this research and also found that they respond to each other.

In the entrepreneurial process addressed in the Timmons Model, the shape, size, and depth of the opportunity establish the required shape, size, and depth of both the resources and the entrepreneurial team 


\section{Yeh \& Chang}

(Timmons and Spinelli, 2008:111). Creation, exploration, and identification of opportunities is at the heart of Timmons Model. In comprehending of opportunity, first is to emphasize on market readiness, the consumer trends and behaviors that look for new products or services. Timmons stresses that in the process of entrepreneurship comprising the ambiguity of opportunities, market uncertainty, capital market risks and changes in the external environment, it is in line with the opportunity exploration competencies and the opportunity exploitation competencies of this study. With respect to the entrepreneurial team element of the Timmons Model (Timmons, 1999), entrepreneurship must rely on entrepreneurial leadership, creativity and communication capabilities to solve problems which also supports the strategic competencies and relationship competencies in this study. In the resources element of the Timmons Model, extraordinary entrepreneurs ingeniously design creative and flexible strategies to lead and acquire control of resources (2008:112), so that start-up microenterprise can accomplish their goals successfully. Likewise, this works in concert with the organizing competencies and strategic competencies in this study. Overall, these six competencies assist the entrepreneur to function in the business and find the balance between opportunity, resources and the entrepreneurial team (Kodithuwakhu and Rosa, 2002). They depend on business management and technical skills. These competencies are also supported by the literature as interdependent and complementary categories required by entrepreneurs in order to succeed (Kodithuwakhu and Rosa, 2002; Mitchelmore and Rowley, 2010; Rwigema and Karungu, 1999). This proposed framework of the six entrepreneurial competencies has the potential to be valuable as it is further developed to be utilized as a structure for subsequent research and discussion upon the practice and advancement of microentrepreneurship.

\section{LIMITATIONS AND FUTURE DIRECTIONS}

This study has a number of limitations that future research can describe. A sample size is one of the limitations to exist in this study. The results are based on a five cases of microenterprises analysis, suggesting that the results may not be generalized, even though they appear to be appropriate to this specific population. More information may be obtained from a larger sample size, other population of microenterprises at various industrial types or in various geographical locations. Another limitation is the 
International Journal of Management, Economics and Social Sciences

research design, which did not provide theory driven argument building to link the dependent and independent variables in this study theoretically. In the literature, there is no existing theory, made in a way consistent with scientific approach, to interpret the nature of the relationships between these entrepreneurial competencies and entrepreneurial performance. Therefore, a mixed-method of how entrepreneurial competencies influence the performance of micro-entrepreneurship can be conducted for future research. By utilizing both interviews and surveys, the researchers can acknowledge that other more variables related to demographic, social, cultural, political, religious, technological, and environmental factors along with the existing factors may furnish more effective theoretical framework and insights in examining the entrepreneurial competencies, entrepreneurial practices, and micro-entrepreneurs' perception of entrepreneurial competencies impacting their entrepreneurial performance.

\section{REFERENCES}

Ahmad, N. H. (2007). A cross cultural study of entrepreneurial competencies and entrepreneurial success in SMEs in Australia and Malaysia. Unpublished Thesis, University of Adelaide, South Australia. Retrieved March 15, 2018, from ebooks.adelaide.edu.au/dspace/bitstream/24 40/48199/2/01front.pdf.

Ahmad, N. H., Ramayah, T., Wilson, C. \& Kummerow, L. (2010). Is entrepreneurial competency and business success relationship contingent upon business environment? A study of Japanese SMEs. International Journal of Entrepreneurial Behavior and Research, 16(3): 182-203.

Aldrich, H. E. (1999). Organizations evolving. Thousand Oaks: CA, Sage.

Baron, R. \& Ensley, M. D. (2006). Opportunity recognition as the detection of meaningful patterns: Evidence from comparisons of novice and experienced entrepreneurs. Management Science, 52(9): 1331-1344.

Baron, R. A. \& Markman, G. D. (2003). Beyond social capital: The role of entrepreneurs' social competence in their financial success. Journal of Business Venturing, 18(1): 41-60.

Bartlett, C. A. \& Ghoshal, S. (1997). The myth of the genetic manager: New personal competencies for new management roles. California Management Review, 40(1): 92-116.

Baum, J. R. (1994). The relationship of traits, competencies, motivation, strategy and structure to venture growth. Unpublished Doctoral Dissertation, University of Maryland, College Park, MD.

Bird, J. (1995). Towards a theory of entrepreneurial competency: Advances in entrepreneurship, firm emergency and growth. JA/ Press, 51-72.

Block, Z. \& MacMillan, I. C. (1985). Milestones for successful venturing planning. Harvard Business Review, 63(5): 84-90.

Botha, M. Vuuren J. V. \& Kunene, T. (2015). An integrated entrepreneurial performance model focusing on the importance and proficiency of competencies for start-up and established SMEs. Business Management, 46(3): 55-65.

Chandler, G. N. \& Hanks, S. H. (1994). Market attractiveness, resource-based capabilities, venture strategies, and venture performance. Journal of Business Venturing, 9(4): 331-349.

Chandler, G. N. \& Jansen, E. J. (1992). Founder's self-assessed competence and venture performance. Journal of Business Venturing, 7(3): 223-236.

Chao, W. H. (2003). APEC microenterprise issues: Also on the development of Taiwan's microenterprises. Taiwan Economic Research Monthly, 25(12): 23-27.

Choi, R., Lévesque, M. \& Shepherd, D. A. (2008). When should entrepreneurs expedite or delay opportunity exploitation? Journal of Business Venturing, 23(3): 333-355. 


\section{Yeh \& Chang}

Choi, Y. R. \& Shepherd, D. A. (2004). Entrepreneurs' decisions to exploit opportunities. Journal of Management, 30, 377-395.

Gasse, Y., d' Amboise, G., Simard, G. \& Lasker, K. (1997). Entrepreneurial-managerial competencies and practices of growing SMEs: Summary of results from an empirical study (preliminary). Working paper no. 15-23, Centre for Entrepreneurship and SME and Entrepreneurial Laval, University Laval, Quebec.

Godfrey, P. \& Gregerson, H. (1999). Where do resources come from? A model of resource generation. The Journal of High Technology Management Research, 10(1): 37-60.

Hatch, J. \& Zweig, J. (2001). Strategic flexibility: The key to growth. Lvey Business Journal, 65(4): 44-47.

Karra, A. N., Nelson, J. \& Tracey, P. (2008). Building the born global firm: Developing entrepreneurial capabilities for international new venture success. Long Range Planning, 41(4): 440-458.

Kirzner, I. M. (1979). Perception, opportunity, and profit: Studies in the theory of entrepreneurship. Chicago: University of Chicago Press.

Kodithuwakhu, S. S. \& Rosa, P. (2002). The entrepreneurial process and economic success in a constrained environment. Journal of Business Venturing, 17(5): 431-465.

Krueger, J., Norris, F., Reilly, M. D. \& Carsrud, A. L. (2000). Competing models of entrepreneurial intentions. Journal of Business Venturing, 15(5): 411-432.

Ma, H. \& Tan, J. (2006). Key components and implications of entrepreneurship: A 4-P framework. Journal of Business Venturing, 21(5): 704-725.

Man, W. Y., Lau, T. \& Chan, K. F. (2002). The competitiveness of small and medium enterprises: A conceptualization with focus on entrepreneurial competencies. Journal of Business Venturing, 17, 123-142.

Man, W. Y., Lau, T. \& Snape, E. (2008). Entrepreneurial competencies and the performance of small and medium enterprises: An investigation through a framework of competitiveness. Journal of Small Business and Entrepreneurship, 21(3): 257-276.

Marimuthu, M., Arokiasamy, L. \& Ismail, M. (2009). Human capital development and its impact on business performance: Evidence from developmental economics. The Journal of International Social Research, 2(8): 265-272.

McClelland, D. (1987). Characteristics of successful entrepreneurs. Journal of Creative Behavior, 3, 219-233.

McGregor, J., Tweed, D., Kolb, D. \& Henley-King, J. (2000). Gender and managerial competence: A comparative study of male and female manufacturers. Paper presented at The University of Edinburgh, Edinburgh, Scotland.

Mitchelmore, S. \& Rowley, J. (2010). Entrepreneurial competencies: A literature review and development agenda. International Journal of Entrepreneurial Behavior and Research, 16(2): 92-111.

Moises, K. (2012). Timmons model of the entrepreneurial process. Retrieved June 18, 2018, from https://kimberlymoises.wordpress.com/2012/08/28/timmons-model-of-the-entrepreneurial-process/

Rice, M. (2002). Co-production of business assistance in business incubators: An exploratory study. Journal of Business Venturing, 17, $163-187$.

Rwigema, H. \& Karungu, P. (1999). SME development in Johannesburg's southern metropolitan local council: An assessment. Development Southern Africa, 16(1): 107-124.

Sarason, Y., Dean, T. \& Dillard, J. F. (2005). Entrepreneurship as the nexus of individual and opportunity: A structuration view. Journal of Business Venturing, 21, 286-305.

Schmitt-Rodermund, E. (2004). Pathways to successful entrepreneurship: Parenting, personality, early entrepreneurial competence, and interests. Journal of Vocational Behavior, 65(3): 498-518.

Shane, S. (2000). Prior knowledge and the discovery of entrepreneurial opportunities. Organization Science, 11(4): $448-469$.

Shane, S. (2003). A general theory of entrepreneurship: The individual opportunity nexus. Cheltenham, UK: Edward Elgar.

Small and Medium Enterprise Administration, (2014). Special Report on the Research and Development of Micro-enterprise Finance in Taiwan Institute of Economic Research. Retrieved June 18, 2018, from https://www.moeasmea.gov.tw/dl.asp?filename $=57215255771$.pdf

Soejono, F., Mendari, A. \& Rinamurti, M. (2015). Competency, entrepreneur characteristic and business performance: Study of the pempek business in Palembang. Journal of Indonesian Economy and Business, 30(1): 30-41.

Timmons, J. A. (1989). The entrepreneurial mind. Louisville, KY: Brick House Publication.

Timmons, J. A. (1999). New venture creation (5 $5^{\text {th }}$ ed.). Singapore: McGraw-Hill.

Timmons, J. A. \& Spinelli, S. (2008). New venture creation: Entrepreneurship for the $21^{\text {st }}$ century (8 $8^{\text {th }}$ ed., 111-116). New York: McGrawHill. 
Unger, J. M., Rauch, A., Frese, M. \& Rosenbusch, N. (2011). Human capital and entrepreneurial success: A meta-analytical review. Journal of Business Venturing, 26(3): 341-358.

Vaghely, I. P. \& Julien, P. A. (2008). Are opportunities recognized or constructed? An information perspective on entrepreneurial opportunity identification. Journal of Business Venturing, 25(1): 73-86.

Wen, C. T. \& Hsieh, R. M. (2010). Literature review and future directions of global entrepreneurship monitor. Journal of Entrepreneurship Research, 5(2): 27-48.

Wu, H. L. (2014). 2014 the White Paper on SMEs: 38-42. Small Medium Enterprise Administration, Taipei.

Yin, R. K. (2003). Case study research: Design and methods. London: Sage Publications. 